\title{
Pathway analysis of gene expression data from colonic biopsies distinguishes salmon from cod consumers
}

\author{
G. Majsak-Newman ${ }^{1,4}$, G. Hooiveld ${ }^{2}$, G. K. Pot ${ }^{2}$, L. J. Harvey ${ }^{1}$, J. F. Doleman ${ }^{1}$ and E. K. Lund ${ }^{1,3}$ \\ ${ }^{1}$ Institute of Food Research, Norwich, NRI IUA, ${ }^{2}$ Division of Human Nutrition, Wageningen University, NL, \\ ${ }^{3}$ Independent Consultant, Norfolk, ${ }^{4}$ Norfolk and Norwich University Hospital NHS Foundation Trust
}

Observational studies suggest a possible protective effect of fish consumption in relation to colorectal cancer ${ }^{(1)}$ and such benefits are generally attributed to the high $n$-3 PUFA content of some species ${ }^{(2)}$. However, our recent 6-month intervention study, FISHGASTRO, was unable to demonstrate any significant difference in conventional markers of colonic health in salmon as compared to cod consumers $^{(3)}$. The aim of this study was to assess whether gene expression analysis can provide more sensitive markers of exposure to dietary fish oils.

Colonic biopsies were collected from patients with normal mucosal morphology attending gastroenterology clinics in the UK and the Netherlands before and after fish intervention ( $300 \mathrm{~g} /$ week) with either salmon providing c. $1.5 \mathrm{~g} n-3 \mathrm{PUFA} / \mathrm{d}(n=15)$ or cod $(n=16)$. Gene expression was assessed by microarray analysis. A range of bioinformatics tools was employed to compare differences in biological pathways and processes changed by the intervention in the two groups and with gene sets known to be affected in colonic disease.

Change in expression of 1202 genes was significantly different $(p<0.05)$ in salmon as compared to cod consumers $(>1.2$ FC) but this effect was absent after $p$-values were corrected for multiple testing using a false discovery rate (FDR) method ${ }^{(4)}$. However, cluster analysis clearly separated cod from salmon consumers with the exception of two individuals. Gene set enrichment analysis was carried out to compare change in salmon consumers versus change in cod consumers and overlapping gene-sets were identified using Cytoscape software in combination with the Enrichment Map plugin ${ }^{(5,6)}$. This analysis revealed that salmon consumption was associated with significantly lower expression of $>50$ key biological processes as compared to cod consumers, while only 10 biological processes were more highly expressed in salmon consumers. The overlapping gene sets containing the most significantly altered gene sets are shown in the table. Comparison with changes in gene expression patterns from previously published data sets identified 17 common biological functions associated with colorectal cancer and 11 associated with inflammatory bowel disease.

In summary, intake of $n$ - 3 rich fish such as salmon differentially affects gene expression in colonic biopsies as compared to cod consumption. It is currently too early to fully interpret these data but this approach shows considerable promise in helping to overcome the issues related to the lack of good biomarkers in understanding how diet may impact on cancer risk. Functional analysis has highlighted novel potentially interesting areas for biomarker development.

\begin{tabular}{llc}
\hline Decreased in salmon consumers & $* \mathrm{q}=$ & Increased in salmon consumers \\
\hline Cell membrane organisation/golgi function & $<0.001$ & Ribosomal function/translation \\
Unfolded protein response (IRE1alpha) & $<0.001$ & Electron transport chain \\
GTPase activity & $<0.001$ & Metab. branched chain amino acids \\
ERK/MAPK pathway & 0.001 & AP-1 transcription factor network \\
Protein processing in ER & 0.001 & Chromatin remodelling \\
\hline
\end{tabular}

*FDR q value for most significant pathway/process in overlapping gene-set.

1. Geelen A, Schouten JM, Kamphuis C et al. (2007) Am J Epidemiol 166, 1116-1125.

2. Lund EK (2013) Food Chem In press.

3. Pot GK, Majsak-Newman G, Geelen A et al. (2009) Am J Clin Nut 90, 354-361.

4. Storey JD \& Tibshirani R (2003) Proc Nat Acad Sci 100, 9440-9445.

5. Shannon P, Markiel A, Ozier O et al. (2003) Genome Res 13, 2498-2504.

6. Stojmirovic A, Bliskovsky A \& Yu YK (2012) Bioinformatics 28, 893-894. 